\title{
Numerical Study of Geosynthetic-Reinforced Soil Wall Subjected to Static Footing Loading
}

\author{
Ananya Srivastava, Sagar Jaiswal, Vinay Bhushan Chauhan* \\ Department of Civil Engineering, Madan Mohan Malaviya University of Technology, Gorakhpur, India \\ Received 13 November 2020; received in revised form 30 December 2020; accepted 15 January 2021 \\ DOI: https://doi.org/10.46604/peti.2021.6693
}

\begin{abstract}
This study intends to examine the behavior of a GRS wall with static footing loading above it, while varying the positions of the footing. For the study of behavior of such complex structure, finite element modeling is handy and enables to look into the various stress/strain developed in the numerical model. In view of the above, a series of finite element (FEM) simulations using a software (Optum G2) is performed for the analysis of the GRS wall. The governing parameters, such as footing width (B), reinforcement length (L), offset distance (D), are evaluated and the effect of these factors on the ultimate bearing capacity (q) and settlement (s) of the footing is presented in this study. The results depict that the settlement of the footing substantially reduced in the range of $36 \%$ and its ultimate bearing capacity is increased to $42 \%$ more than the conventional retaining walls.
\end{abstract}

Keywords: GRS wall, static footing loading, FEM, ultimate load-bearing capacity

\section{Introduction}

Geosynthetic-reinforced soil (GRS) walls are now preferred more than the traditional gravity retaining walls as such walls can withstand much larger surcharge loads than conventional retaining walls owing to their increased stability and load-bearing capacity. In case of bridge abutment, the wall usually used are bulky gravity walls that have to be supported by the piles/group of piles. However, GRS walls when implied as bridge abutments such conditions does not arise that is why GRS wall is preferred for such a construction. This also aids in reducing the bridge bumps at the edge of an approaching embankment and an adjacent bridge, thus, creating a more economic and safer solution. Sometimes the backfill is used as a construction bed for building structure by laying the shallow foundation. It is therefore necessary to understand the behavior of footing resting on the backfill of GRS wall.

The previously available literature attained through various field observations, laboratory and numerical simulations also suggested that the ultimate bearing capacity and the settlement characteristics of the footing situated on the backfill of the wall were enhanced by adopting suitable arrangement of the reinforcements in the soil mass [1-4]. The outcomes from a limited number of field tests and laboratory model tests highlight the fact that these GRS walls when subjected to static footing loads perform far better than the traditional gravity walls in terms wall deformations, ultimate load-bearing capacity and settlement of the footing [5]. However, when exposed to ultra-violet rays, the polymeric reinforcement may degrade its original strength.

According to the AASHTO [6] and the FHWA [7] design guidelines, the stability of the reinforced soil retaining walls is guaranteed by three components namely, the retained soil mass, reinforced soil mass, and foundation soil. The retained soil mass is restrained by the reinforced soil mass, the active zone of the reinforced soil mass is restrained by the reinforcement

* Corresponding author. E-mail address: chauhan.vinaybhushan@gmail.com 
layers which are embedded in the passive zone and both the retained and reinforced soil masses are supported by the foundation soil. When a structure, is planned close to bridge abutment such as a footing is situated on the reinforced wall, its stability is influenced by the load which is supported by the footing. Structural symmetry does not exist for footing, as on one side the facing of the GRS wall works as a boundary while on the other side there lies an infinite soil mass, thus making its analysis quite complex and highlighting the necessity to study its behavior thoroughly. Moreover, as the position of the footing varies (i.e., near or far from the wall facing), the lateral displacement of the wall (z), load-bearing capacity (q) and the settlement of the footing ( $\mathrm{s}$ ) varies accordingly and the analysis become a tedious task.

Researchers have previously conducted many numerical analyses on the behavior of the GRS walls carrying a strip footing considering two dimensions (2D) of the proposed model under the plane strain conditions [8-14]. The results so obtained reestablished the superiority of the reinforced earth structures over the traditional earth retaining structures by their excellent serviceability and load-bearing capacity. However, very limited studies, conducted so far, can provide a satisfactory result that can clearly define the relationship between the important controlling parameters (position of the footing on the GRS wall) and the aberration in the behavior and performance of the GRS wall under such fluctuating conditions [3, 15-17]. The previously conducted studies fall short in providing a unanimous opinion regarding the optimum values of the essential parameters being used in the finite element modeling of the above-mentioned structure. Only a few studies have been able to establish a concrete load (q)-settlement (s) behavior of footings positioned on the GRS walls. Limited work has yet been done to explore the performance of the GRS walls while varying the location of the footing. Nevertheless, an exhaustive performance report is yet to be made which can provide an extensive database for the optimal construction and efficient design suitable for a GRS wall bearing the footing load. Henceforth, this paper presents FEM based numerical study, conducted through a sequence of numerical model simulation to assess the effects of the governing parameters such as offset distance of the static footing load, the width of the footing, and length of geosynthetic reinforcement. The effect of these factors on the bearing capacity of the footing load on the GRS wall and performance of the overall structure is evaluated based on criterion namely, lateral deflection of the wall facing, backfill surface settlement of GRS wall, and the vertical settlement of the footing. Moreover, a comparative analysis has been performed on a gravity wall and the GRS wall of similar dimensions and loading conditions to investigate the load-bearing capacity and settlement characteristics of both the walls. This study also aims to inspect the effect caused by the modes of connection between the wall facing and the geosynthetic reinforcement and to identify the probable modes of failure of the wall.

\section{Methods}

\subsection{Numerical modeling in the present study}

The numerical analysis in the present study has been performed by a numerical computational tool Optum G2 [18], a finite element program dedicated to geotechnical deformation and stability analysis under plane strain conditions. This software empowers to use the graphical user interface and select the appropriate elements for the better accuracy of the load-bearing capacity characteristics while iterating the numerical simulations. The GRS wall of height, $\mathrm{H}=6 \mathrm{~m}$ is considered in the current study is reinforced using a geogrid element and having a rigid facing (as blocks of concrete) and is subjected to static footing loading. A gravity wall of similar height $(6 \mathrm{~m})$ is also constructed under the same guidelines to provide comparative results in this study.

The configuration of the GRS wall numerical model is constructed according to the FHWA [7] design recommendations. Figs. 1 and 2 show the GRS wall with footing and gravity wall with footing considered in this study respectively. For the GRS wall and footing system, a leveling pad which is a rigid material (concrete) carrying measurements as $2.0 \mathrm{~m} \times 0.2 \mathrm{~m}$ (in altitude) is rested on the soil used in the foundation. Above this, a modular block concrete facing with measurements as $1.5 \mathrm{~m} \times 0.6 \mathrm{~m}$ (in 
altitude) is positioned, over which another layer of backfill soil is deposited which provides a lift of $0.6 \mathrm{~m}$. A geosynthetic layer of the preferred length $(\mathrm{L}=0.7 \mathrm{H}$ to recreate the field construction procedure) is positioned on the backfill soil before placing the subsequent modular block facing. The preceding lift is still maintained such that a section of geosynthetic reinforcement is sealed between the consecutive concrete facings. Then backfill layer is again placed over the geosynthetic layer and this process is reiterated until the required wall height is accomplished. The above process shows the real stress path experienced by the total wall system. Normal supports were utilized to fix the lateral boundaries, as it inhibits the movement of the soil in the lateral direction. The soil at the bottom of the structure was bound by fixed supports to inhibit both vertical and horizontal movement of the soil. The rigid footing (concrete) with dimensions $1.0 \mathrm{~m} \times 0.5 \mathrm{~m}$ is positioned on the wall with varying offset distances (D), which is defined as the distance of the footing from the rigid concrete facing block, as shown in Fig. 1.

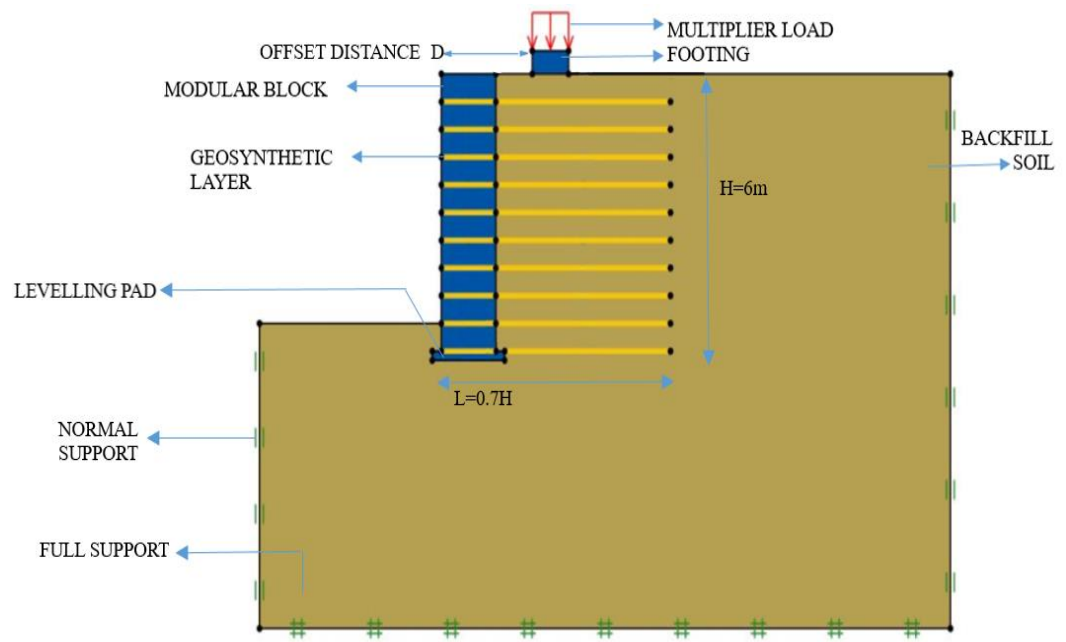

Fig. 1 Geosynthetic-reinforced soil (GRS) wall considered in the present study

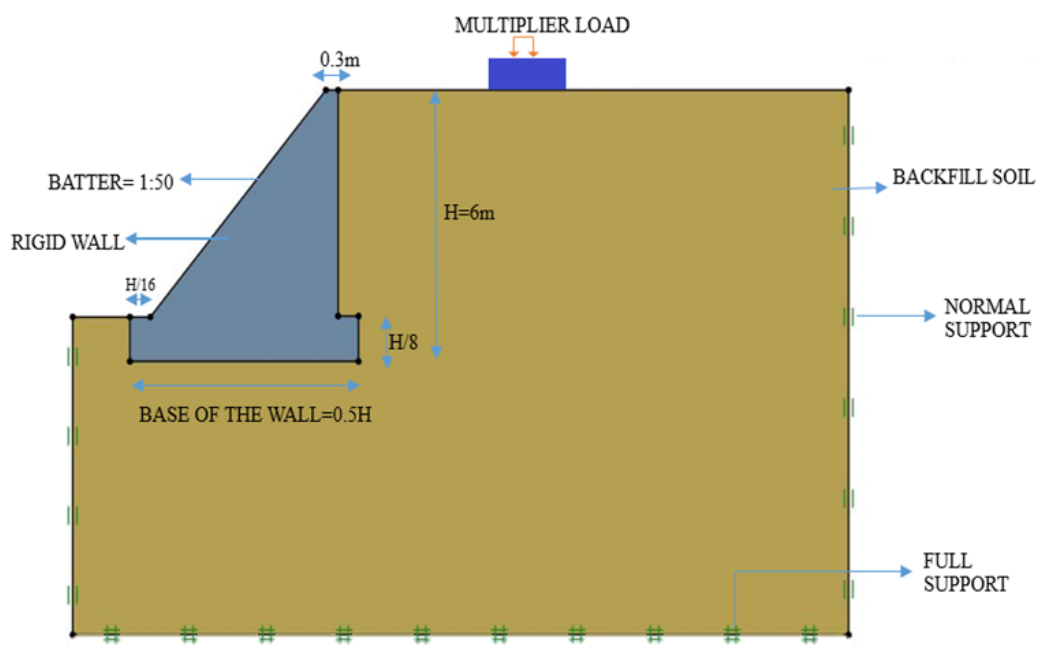

Fig. 2 Gravity wall considered in the present study

The offset distance is varied in the study and the effect of this variation on the GRS wall and the gravity wall is investigated.

\subsection{Material parameters}

The concrete facing blocks, footing, leveling pad, are modeled as rigid materials with unit weight as $25 \mathrm{kN} / \mathrm{m}^{3}$. The backfill soil is considered as an elastoplastic material that follows the Mohr-Coulomb failure criterion following associated flow rule used by various researchers due to its proficiency in reasonably simulating the soil behavior in GRS walls [19-23] having cohesion, $\mathrm{c}=0 \mathrm{kPa}$ and internal friction angle, $\phi=34^{\circ}$, and dry unit weight, $\gamma_{\mathrm{dry}}=19 \mathrm{kN} / \mathrm{m}^{3}$. The reinforcement using geogrid element is considered as an elastic material able to take tensile load only with elastic stiffness (EA) of $1000 \mathrm{kN} / \mathrm{m}$ [24]. 
The mechanism utilized for the transfer of forces between two dissimilar materials is simulated using an elastoplastic interface, bearing the interface coefficient values like 0.7 [24] and 0.8 [25] for geosynthetic-soil and geosynthetic-block interfaces, respectively. These are allocated at all the interfaces in this GRS wall and footing system. Such simulations are carried out using the multiplier elastoplastic analysis in which a set of multiplier loads (shown in Figs. 1 and 2) are incremented in a sequence of steps until collapse load is determined $[24,26]$.

The optimum number of elements present in the mesh primarily governs the efficiency of the numerical model. Moreover, taking a large number of elements for a given mesh becomes time taking procedure for the simulation. On account of the above, a sensitivity analysis is conducted to acquire the ideal number of elements desired for the mesh taken in the present analysis [24-25, 27-28]. The overall number of elements is ranged from 2000 to 6000 with a successive increment of 1000 elements in each simulation. It was found that 4000 elements are optimal for the mesh taken in the current analysis. The selected number of elements produces a very fine mesh for the considered geometry and found to be significant for achieving reasonable performance.

\section{Results and Discussion}

The present study performs a comparative analysis of the performance of the unreinforced gravity wall and the GRS wall under identical loading conditions. The footing was placed at an offset distance $\mathrm{D}=2 \mathrm{~m}$, where the footing is neither too distant from the wall facing nor very near to it and has an even distribution of the reinforcing members beneath the surface. The results obtained from the numerical simulations are presented through a graph of settlement vs incremental load derived by applying the load on the footing in Fig. 3.

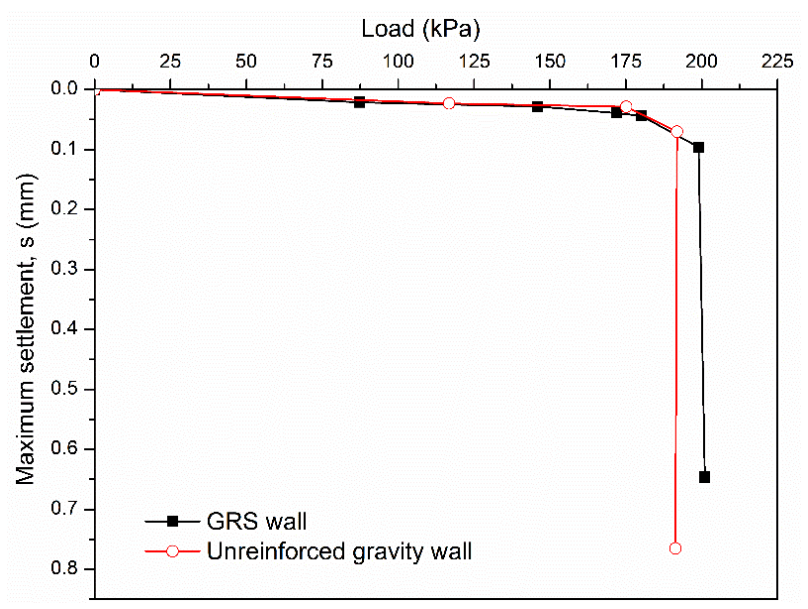

Fig. 3 Maximum settlement of the footing (s) vs applied incremental load on footing resting over a GRS wall and unreinforced gravity wall at offset distance (D) of $2 \mathrm{~m}$

The graph noticeably shows that the settlement (s) of the footing in the GRS wall is lower in magnitude than the settlement obtained in the unreinforced gravity wall as the load increases. The footing situated on the GRS wall experiences a maximum settlement of $63 \%$ with an incremental loading whereas the footing on the unreinforced wall suffers a settlement of $74.94 \%$ with the same offset distance $\mathrm{D}=2 \mathrm{~m}$ in both cases. The load-bearing capacity (q) in the case of a GRS wall is higher than the load-bearing capacity (q) of the unreinforced gravity wall. The difference in the magnitude of settlement characteristics of the footing between GRS wall and conventional retaining wall increases as the height of the wall rises, which suggests the supremacy of GRS walls over the conventional gravity walls. Henceforth, to examine the performance of the GRS wall with a footing load, an extended study was performed to analyze the behavior of the GRS wall and footing under static loading system, while varying the offset distance of the footing. In order to choose the appropriate elastic stiffness (EA) of the geosynthetic, the numerical simulations were performed at various values of ranging from $500 \mathrm{kN} / \mathrm{m}$ to $2000 \mathrm{kN} / \mathrm{m}$ at an interval of $500 \mathrm{kN} / \mathrm{m}$ each to determine the optimum value of EA to economize the design. Through the outcomes of the 
simulations, it was evident that as the elastic stiffness of the reinforcing material increases, the lateral displacement of the wall facing decreases correspondingly [29]. Furthermore, the result indicated the value of elastic stiffness is kept constant at 1000 $\mathrm{kN} / \mathrm{m}$ throughout the study. The settlement of the footing is also affected by footing's offset distance, which is the distance between the wall facing and the position of the footing. Fig. 4 below shows the variation of the D and depicts the effect it produces on the settlement of the footing, w.r.t the incremental load applied due to the footing.

As shown in Fig. 4, the D/B ratio has a significant impact on the settlement characteristics of the footing load situated on the GRS wall. The footing experiences maximum settlement when the D/B ratio is least i.e., 0.5. This can be attributed to the fact that when $\mathrm{D} / \mathrm{B}=0.5$, on one side of the footing there exists a rigid wall facing while on the other side there is a presence of extended reinforcement member, causing uneven reinforcement, due to which the total axial load cannot be endured, leading to the failure of the wall and excessive settlement of the static footing. As the D/B ratios increase from 1.0 to 6.0, again at those positions of the footing where the reinforcements under the soil are almost equally distributed, the settlement values are low in magnitude. On the other hand, when D/B ratio increases and the footing is placed beyond the influence of reinforcement members, the settlement is higher. The footing settlement increases by $53 \%$ as the position of footing is varied from $\mathrm{D} / \mathrm{B}=0.5$ to 6.0. This indicates that the footing must be placed at such a position where the reinforcement is equally distributed with minimum influencing factors, to receive maximum load-bearing capacity (q) and least settlement (s). The results of this study demonstrates that the footing that rests over the backfill of the GRS wall should neither be very close to the rigid block nor very far away. For better results, the footing must be placed in the range of $\mathrm{D} / \mathrm{B}=2.0-4.0$. The results of the load and the normalized settlement of the footing (s/B) are presented in the form of the plot (Fig. 4), which follows the same variation trends as depicted by Xiao et al. [30].

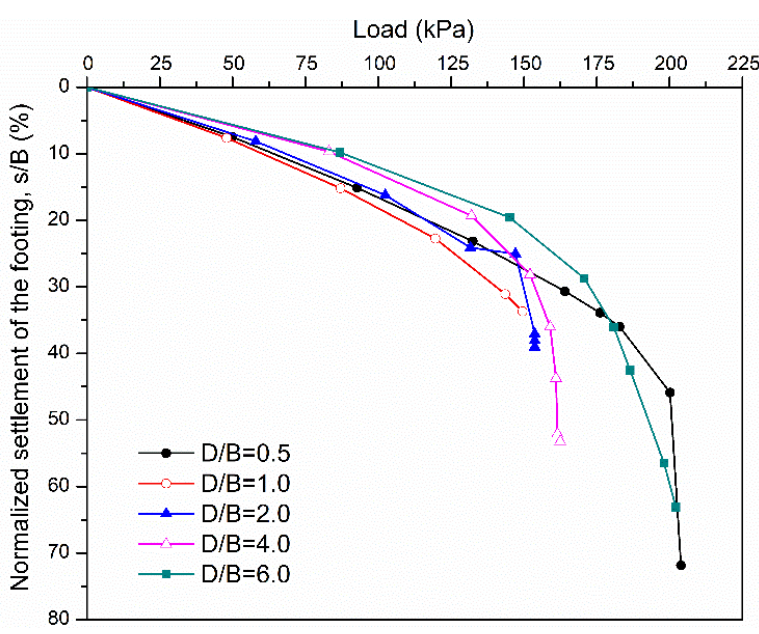

Fig. 4 Variation of load vs normalized settlement of the footing for the various $\mathrm{D} / \mathrm{B}$ ratios

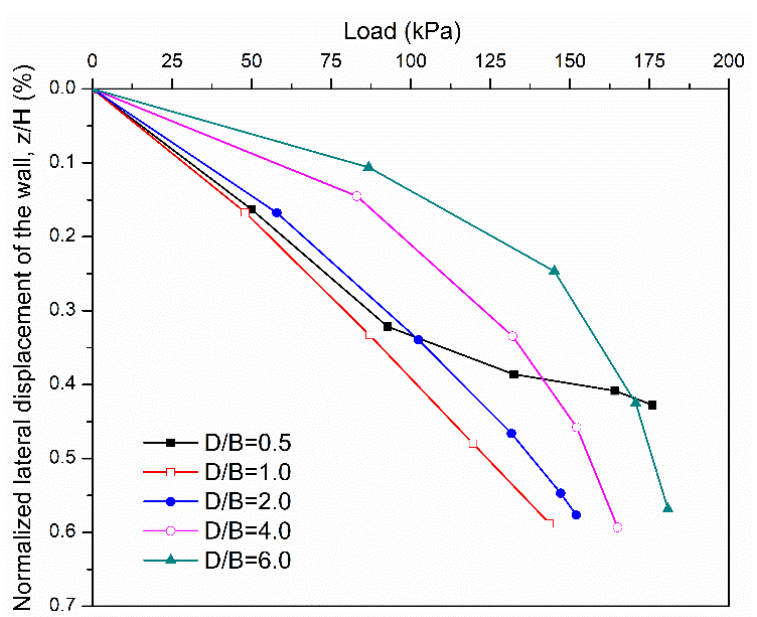

Fig. 5 Variation of load-bearing capacity vs normalized lateral displacement of the wall facing for various $\mathrm{D} / \mathrm{B}$ ratio

The lateral displacement of the wall facing is a prominent serviceability criterion as it may lead to the successive backfill settlement, due to which the surrounding structure resting nearby/backfill surface may be susceptible to failure or distress. Here again, D is known to play a major role in the lateral displacement of the wall facing as load coming through footing pushes the wall outwards to move away from its original position. A comparison of the lateral displacement of the wall facing ( $\mathrm{z}$ ) normalized with the height of the wall $(\mathrm{H})$ versus its load-bearing capacity $(\mathrm{q})$ is made for various D/B values and shown in Fig. 5.

For $\mathrm{D} / \mathrm{B}=0.5$, the possible failure is being intercepted at the upper part of the wall facing, due to which the movement of the upper block is rapid, however, the movement of the lower portion of the wall is not much high. For D/B $=6$, the footing is far away from the wall, and behaves like footing in general cases, whose influence is not greatly observed on the lateral displacement of the wall. Also, at $\mathrm{D} / \mathrm{B}=1$, the lateral displacement is much higher which can lead in serviceability issues. Despite, the $\mathrm{z} / \mathrm{H}$ is lowest at a given load for $\mathrm{D} / \mathrm{B}=2-4$, at which the displacement of the footing is also the minimum. Therefore, this study suggests the optimum value of $\mathrm{D} / \mathrm{B}=2-4$ must be used, depending upon the importance of the structure. 
A similar variation trend is noticed in the result reported by Rahmouni et al. [31] for $\mathrm{D} / \mathrm{B}=1.0$. This can be attributed to the fact that, when the footing is situated closest to the wall, it is surrounded by the rigid wall facing and strong reinforcement beneath the ground. Thus, the load so exerted is being resisted (failure plane intercept) by both the rigid wall facing and reinforcement which is evenly situated causing lesser displacement of the wall facing. Also, the lower wall facing suffers greater displacements than the upper wall facings which are in line with the results of Zheng et al. [32]. When the D/B ratio increases, the influence of reinforcement beneath the footing is reduced due to uneven distribution of reinforcement on the both sides of the footing. Due to this uneven distribution of the load-bearing members, the footing cannot bear the axial load, thus eventually leading to its failure in the form of displacement of the wall facing. When the D/B ratio is varied from 0.5 to 6.0 , the settlement of the footing undergoes a minor raise of approximately $1.6 \%$ in magnitude, but the ultimate bearing capacity of the footing increases by $21 \%$.

A comparison is made for footing resting on the reinforced zone of GRS wall and beyond the reinforcement and depicted in Fig. 6. The present study shows two types of failures, a failure above the topmost layer of reinforcement and general failure within the reinforced zone. When geosynthetic reinforcement distorts locally due to applied stress below the base of the footing, it generates tension that carries a vertical resistance component, i.e., an uplift force as shown in the Fig. 6. In Fig. 6(a), the heaving of the soil on the left of the footing is found to be lesser when compared to the right due to obvious reason, as a rigid wall is present on the left side of the. Usually, in case of shallow foundation, the zone of shear failure extends up to a depth of 2B below the footing. The first layer of reinforcement is at a depth of $0.6 \mathrm{~m}$ from the ground level, in this case the failure plane/wedge does not extend below the reinforcement provided and gets confined in the local zone of soil resting above the first reinforcement layer. The laterally outward displacement coordinates signify the wall deformation caused as the footing sinks into the ground when the stress exceeds the bearing capacity. Also, a severe stress zone is getting developed beneath the footing which is limited to depth of $1.8 \mathrm{~B}$, however, no interference between the path of the failure plane and the reinforcement occurs as the tensile reinforcement is carrying the load by the footing (Fig. 6(b)).

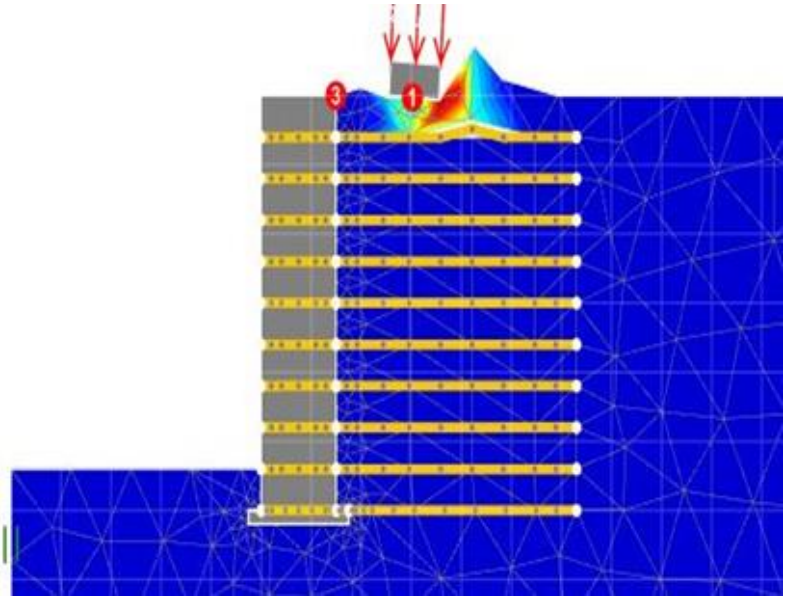

(a) Generation of failure zone when the footing lies above the reinforcement

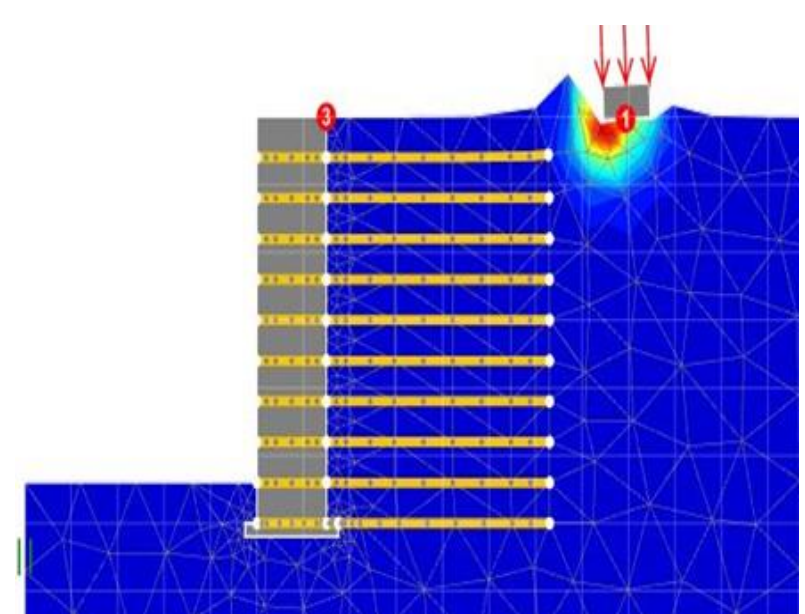

(b) Generation of failure zone when the footing lies beyond the reinforcement

Fig. 6 The potential failure pattern of the footing

\section{Conclusions and Recommendations}

In the present study, the performance of a $6 \mathrm{~m}$ high GRS wall under static footing load was assessed and the influence of the governing factors namely the reinforcement length (L), offset distance (D), and the width of the footing (B), on the ultimate load-bearing capacity (q), the settlement of the footing (s) and horizontal deformation of the facing (z) was evaluated. A comparative study was performed between the GRS wall and gravity wall of similar dimensions, to investigate the variance in their performance and behavior under analogous loading conditions. This study also demonstrates that there exists an optimum 
footing-facing distance (D) which gives the maximum value of load-bearing capacity and least settlement; however, the determination of ultimate load-bearing capacity is wisely based on the backfill surface settlement induced from the footing load which may influence the serviceability of the nearby existing structure. Based on this study, the following conclusions can be drawn:

The lateral deformation of the wall facing was lesser than 5\% when the footing load was nearest to the facing of the wall, at a reinforcement length of $0.7 \mathrm{H}$. As the offset distance increased from $1.0 \mathrm{~m}$ to $6.0 \mathrm{~m}$ the deformation of the wall facing increased by $26 \%$ than the initial conditions. The GRS walls had the maximum load-bearing capacity $\mathrm{q}$ occurring at $\mathrm{D} / \mathrm{B}=0.5$ and 6.0. But these ratios are not feasible for the safe design of the footing placed over the GRS wall as at these ratios, the footing shows excessive settlement. The settlement of the footing load increases, when the location of the footing goes beyond the influence of the reinforcement zone, due to the uneven distribution of the reinforcing members. Therefore, this study suggests an optimal ratio of $\mathrm{D} / \mathrm{B}=2-4$ for the placement of the footing above the GRS wall. There occurs an increment of $53 \%$ in the settlement when the $\mathrm{D} / \mathrm{B}$ ratio is varied from 0.5 to 6.0 .

\section{Conflicts of Interest}

The authors declare no conflict of interest.

\section{References}

[1] K. Kazimierowicz-Frankowska, "A Case Study of a Geosynthetic Reinforced Wall with Wrap-Around Facing," Geotextiles and Geomembranes, vol. 23, no. 1, pp. 107-115, February 2005.

[2] K. Hatami and R. J. Bathurst, "Numerical Model for Reinforced Soil Segmental Walls Under Surcharge Loading,” Journal of Geotechnical and Geoenvironmental Engineering, vol. 132, no. 6, pp. 673-684, June 2006.

[3] D. T. Bergado, J. C. Chai, and N. Miura, "FE Analysis of Grid Reinforced Embankment System on Soft Bangkok Clay," Computers and Geotechnics, vol. 17, no. 4, pp. 447-471, 1995.

[4] M. S. Won and Y. S. Kim, "Internal Deformation Behavior of Geosynthetic-Reinforced Soil Walls," Geotextiles and Geomembranes, vol. 25, no. 1, pp. 10-22, February 2007.

[5] M. T. Adams and J. G. Collin, "Large Model Spread Footing Load Tests on Geosynthetic Reinforced Soil Foundations," Journal of Geotechnical and Geoenvironmental Engineering, vol. 123, no. 1, pp. 66-72, January 1997.

[6] AASHTO, LRFD Bridge Design Specifications, Customary U.S. Unit. American Association of State Highway and Transportation Officials, Washington, DC, USA, 2012.

[7] R. R. Berg, B. R. Christopher, and N. C. Samtani, "Design of Mechanically Stabilized Earth Walls and Reinforced Soil Slopes,” FHWA, Washington, DC, Rep. No. FHWANHI-10-024, 2009.

[8] Y. Zheng and P. J. Fox, "Numerical Investigation of Geosynthetic-Reinforced Soil Bridge Abutments Under Static Loading," Journal of Geotechnical and Geoenvironmental Engineering, vol. 142, no. 5, 04016004, May 2016.

[9] H. I. Ling and D. Leshchinsky, "Finite Element Parametric Study of The Behavior of Segmental Block Reinforced-Soil Retaining Walls", Geosynthetics International, vol. 10, no. 3, pp. 77-94, June 2003.

[10] K. Hatami and R. J. Bathurst, "Development and Verification of a Numerical Model for the Analysis of Geosynthetic Reinforced Soil Segmental Walls Under Working Stress Conditions,” Canadian Geotechnical Journal, vol. 42, no. 4, pp. 1066-1085, August 2005.

[11] E. Guler, M. Hamderi, and M. M. Demirkan, "Numerical Analysis of Reinforced Soil-Retaining Wall Structures with Cohesive and Granular Backfills," Geosynthetics International, vol. 14, no. 6, pp. 330-345, December 2007.

[12] B. Huang, R. J. Bathurst, and K. Hatami, "Numerical Study of Reinforced Soil Segmental Walls Using Three Different Constitutive Soil Models," Journal of Geotechnical and Geoenvironmental Engineering, vol. 135, no. 10, pp. 1486-1498, October 2009.

[13] B. Huang, R. J. Bathurst, K. Hatami, and T. M. Allen, "Influence of Toe Restraint on Reinforced Soil Segmental Walls," Canadian Geotechnical Journal, vol. 47, no. 8, pp. 885-904, August 2010.

[14] S. H. Mirmoradi and M. Ehrlich, "Numerical Evaluation of the Behavior of GRS Walls with Segmental Block Facing under Working Stress Conditions," Journal of Geotechnical and Geoenvironmental Engineering, vol. 141, no. 3, March 2015 . 
[15] D. T. Bergado and C. Teerawattanasuk, "2D and 3D Numerical Simulations of Reinforced Embankments on Soft Ground," Geotextiles and Geomembranes, vol. 26, no. 1, pp. 39-55, February 2008.

[16] J. Han, Principles and Practice of Ground Improvement. John Wiley \& Sons, 2015.

[17] R. K. Rowe and S. K. Ho, "Horizontal Deformation in Reinforced Soil Walls," Canadian Geotechnical Journal, vol. 35, no. 2, pp. 312-327, April 1998.

[18] “Optum G2,” http://www.optumce.com/, 2020.

[19] D. Leshchinsky, Y. Hu, and J. Han, "Limited Reinforced Space in Segmental Retaining Walls," Geotextiles and Geomembranes, vol. 22, no. 6, pp. 543-553, December 2004.

[20] J. Huang, R. L. Parsons, J. Han, and M. Pierson, "Numerical Analysis of a Laterally Loaded Shaft Constructed Within an MSE Wall," Geotextiles and Geomembranes, vol. 29, no. 3, pp. 233-241, June 2011.

[21] K. H. Yang and C. N. Liu, "Finite Element Analysis of Earth Pressures for Narrow Retaining Walls," Journal of GeoEngineering, vol. 2, no. 2, pp. 43-52, August 2007.

[22] J. Han and D. Leshchinsky, "Analysis of Back-to-Back Mechanically Stabilized Earth Walls," Geotextiles and Geomembranes, vol. 28, no. 3, pp. 262-267, June 2010.

[23] Y. Yu, R. J. Bathurst, and T. M. Allen, "Numerical Modelling of the SR-18 Geogrid Reinforced Modular Block Retaining Walls," Journal of Geotechnical and Geoenvironmental Engineering, vol. 14, no. 5, 04016003, May 2016.

[24] S. Jaiswal, A. Srivastava, and V. B. Chauhan, "Performance of Strip Footing on Sand Bed Reinforced with Multilayer Geotextile with Wraparound Ends," Proceedings of Indian Geotechnical Conference, 2020, pp. 192-202.

[25] A. Srivastava and V. B. Chauhan, "Numerical Studies on Two-Tiered MSE Walls Under Seismic Loading," SN Applied Sciences, vol. 2, no. 10, pp. 1-7, September 2020.

[26] K. Krabbenhoft, A. Lyamin, and J. Krabbenhoft, “OptumG2: Theory, Optum Computational Engineering,” 2017.

[27] A. Pandey and V. B. Chauhan, "Evaluation of Pull-Out Capacity of Helical Anchors in Clay Using Finite Element Analysis," Geo-Congress 2020: Modeling, Geomaterials, and Site Characterization, pp. 60-68, February 2020.

[28] S. Jaiswal, A. Srivastava, and V. B. Chauhan, "Numerical Modeling of Soil Nailed Slope Using Drucker-Prager Model," Proceedings of Geo-Science and Geo-Structures, 2020.

[29] Y. Zheng and P. J. Fox, "Numerical Investigation of the Geosynthetic Reinforced Soil-Integrated Bridge System under Static Loading," Journal of Geotechnical and Geoenvironmental Engineering, vol. 143, no. 6, 04017008, June 2017.

[30] C. Xiao, J. Han, and Z. Zhang, "Experimental Study on Performance of Geosynthetic-Reinforced Soil Model Walls on Rigid Foundations Subjected to Static Footing Loading," Geotextiles and Geomembranes, vol. 44, no. 1, pp. 81-94, February 2016.

[31] O. Rahmouni, A. Mabrouki, and D. Benmeddour, "Numerical Study of the Bearing Capacity of a Strip Footing Near of Geosynthetic-Reinforced Soil Retaining Walls," 4th International Conference on New Developments in Soil Mechanics and Geotechnical Engineering, June 2016, pp. 633-638.

[32] Y. Zheng, P. J. Fox, and P. Benson Shing, "Numerical Study of Deformation Behavior for a Geosynthetic-Reinforced Soil Bridge Abutment under Static Loading," International Foundations Conference and Equipment Expo, pp. 1503-1512, 2015.

Copyright $\odot$ by the authors. Licensee TAETI, Taiwan. This article is an open access article distributed under the terms and conditions of the Creative Commons Attribution (CC BY-NC) license (https://creativecommons.org/licenses/by-nc/4.0/). 